\title{
Total Dance: Examining Interdisciplinarity In/Through Dance
}

\author{
整体舞蹈 : 审视舞蹈中的跨学科性 \\ Stefania Mylona \\ Movement Teacher and Artist, Greece
}

\begin{abstract}
In this paper, I aim to argue about the potential of dance as movement that creates total dance in the sense of E. T. Kirby's concept of total theater or Wagner's Gesamtkunstwerk, total artwork. Movement creates moving images, moving sculptures, and moving sounds, allowing bodies to reach their full performance potential in what I term total dance. By total dance, I refer to a moving sculptural assemblage that entails moving images and creates moving sounds. Through this analysis of total dance, I aim to propose that both movement analyses and corporeality are inherently interdisciplinary.
\end{abstract}

Keywords: dance, performance, sculpture, cross-arts, interdisciplinarity

\section{摘要}

本文旨在根据E.T.Kirby的整体戏剧或瓦格纳的整体艺术作品Gesamtkunstwerk的概 念，来探讨舞蹈作为创造整体舞蹈的动作的潜力。动作创造了移动的图像、移动的雕塑 和移动的声音，使得身体在作者所讲的整体舞蹈中充分发挥其表演潜力。作者叙述的整 体舞蹈是指一个移动的雕塑组合，它包括移动的图像和创造移动的声音。通过对整体舞 蹈的分析，作者旨在提出动作分析和身体性在本质上是跨学科的。

关键词: 舞蹈，表演，雕塑，跨领域艺术，多学科性

\section{Introduction}

In this paper, I aim to argue about the potential of dance as movement that creates total dance in the sense of E. T. Kirby's concept of total theater or Wagner's Gesamtkunstwerk, total artwork. Movement - when we extract dance esthetics - might create moving images, moving sculptures, and moving sounds, allowing bodies to reach their full performance potential in what I term total dance. Performers' bodies can even act as scenographic props. What a body can do begins (with)in movement.

I will depart on a choreological analysis of performance works by me. The term choreology was introduced by Rudolf Von Laban in 1926 and is broadly defined as the scholarly study of dance. Before launching into a detailed analysis of my paradigms, I would also like to briefly introduce Laban's choreological model based on his documentation in The Mastery of Movement (1950). Laban's model of movement analysis examines four basic dance elements: time, effort, shape, and space. However, its complexity is founded in the fact that each of these dance elements includes the 
other three. Thus, for instance, we may examine the shape of time, its space, and effort.

Laban noted the "outward" streaming of movement continuity (1950, ed. 1971, p. 84), which partially explains why release-based techniques were adopted by expressionist dance theater practices. However, the replacement of effort as tension, with effort as expression of flow, has led to a reduction in the capacity of form to create shapes. In Laban's choreological model, dance effort the "inner impulses from which movement originates" (Laban, 1950, ed. 1971, p. 10) was emphatically seen in relation to shape design. Furthermore, in performance movements of dance, realist bodily movement becomes prominent over dance flow. Choreology suggests a practical commitment as Laban theorists Valerie Preston-Dunlop and Anna Sánchez-Colberg emphasize in Dance and the Performative (2002). By looking at choreology as a practical theory of dance, they locate it within a performative field. I intend to utilize Laban's model in the intersisciplinary cross-arts context for analyzing moving images, moving sculptures, and moving sounds.

I will take on a pragmatic approach to movement to show how bodily movement can create total dance. In my analysis, I will utilize Laban's movement model to explain how bodily movement intersects with images, sculptures, and sounds. Laban's model of movement analysis can be applied in the interdisciplinary performance context where effort is the basic element of movement, space is the basic element of images, shape design is the basic element of sculptures, and time is the basic element of sound. However, as in Laban's model, each element entails the other four elements. For example, there is the effort of space, the effort of shape, and the effort of time or the shape of time. We can then speak of the effort of moving sculptures or shape design and of the shape design of images or space.

I will begin my analysis by examining moving images in solo dances created by me. I will then move onto analyzing moving sculptures or moving bodily assemblages, and lastly, I will analyze the potential of moving bodies to inflict moving sounds. In the end, I plan to show how moving images, moving sculptures, and moving sounds all work simultaneously to produce total dance. Total dance can be performed by a sculptural assemblage containing moving images and moving sounds.

\section{Moving Images}

Figures 1 and 2 show how the moving body has visually distorted the form of the human body. Shape design to use one of Laban's terms has been distorted. Some body parts are projected forward and toward the viewer, whereas others become obscured. In Figure 1, the torso of the dance has disappeared, and in Figure 2, the length of the legs has been shortened while legs turn in.

Art historian Aby Warburg (1866-1929) had been interested in the Dionysic foundations of Renaissance art and the image in motion. In his attempt to examine the image in motion, he became interested in how Botticelli made the Study for a Composition of Venus Emerging from the Waves by copying a drawing of Antiquity: 


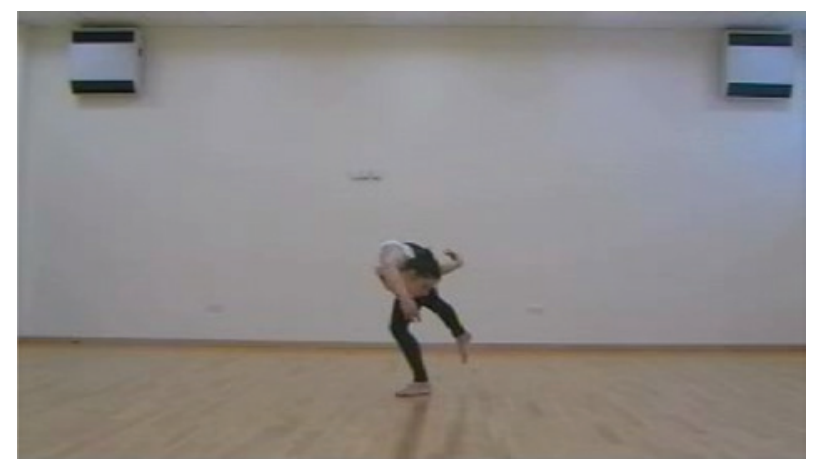

FIGURE 1 | Solo improvisation by Stefania Mylona (2007).

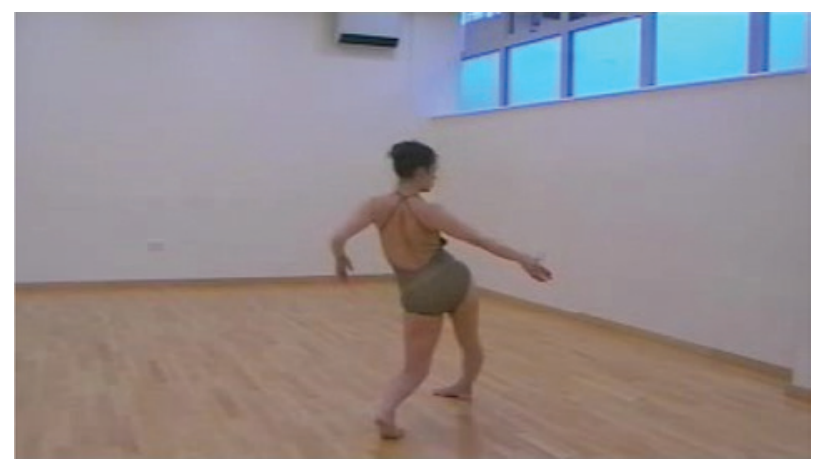

FIGURE 2 | Solo improvisation by Stefania Mylona (2007).

Including its deterioration, to express the phenomena of appearance and disappearance, seeking to reproduce not so much the figure depicted as the act of figuration itself, and the pulsing of presence and absence conditioning it. (Michaud, 2004, p. 72).

Thus, images were seen in motion, particularly by representing their duration through missing body parts that revealed movement continuities. Similarly, my bodily images contain movement through obscured body parts, and in the images, we can see how shape design contains effort.

Philippe-Alain Michaud states that, in Warburg's analysis:

The movement is described as an active dissociation between the fluttering contours of the figure and its mass, which seems to dissolve at the extremities, like a dance introducing disorder to its symmetry, shuttering the measured equilibrium of the static apparition. (p. 71).

Thus, Warburg's analysis of the image in motion was situated in between contour and mass. 
Andreas Huyssen (1995), a professor of literature, suggests that these growing body fragments construct the post-identity frame of postmodernism.

Such images of threatening body fragments, which take a life of their own...causes...anxieties of excess, of flowing over, of unstable bodily boundaries...Indeed, it is important to insist that these experiences of excess are not to be misread as positive expansions of the self...Indeed, we face the paradox that these visions of bodily excess are simultaneously experiences of loss...it is a more totalizing loss, a wiping out of identity. (p. 109)

Despite Huyssen's pessimistic view, I would like to argue that human identity becomes more significant precisely because these bodily excesses also involve losses. It is the combination of making some body parts absent while others become excessive that empowers identity. This effect is reminiscent of Louise Bourgeois' elliptic sculptural forms that turned loss into identity, absence into presence. Bourgeois' anatomical distortions were founded on an elliptic architecture of human forms. Missing or invisible body parts became present through their absence. This was achieved because the viewer could identify with a disappearing humanity through the human references of the form on display. Humanity was thus accentuated through these dehumanized forms.

Dance theorist Dee Reynolds noted Wassily Kandinsky's argument on the kinesthetic possibilities of images and their importance for his move toward abstraction: "He affirmed that scientific discoveries that called the solidity of matter into question...pointed to possible connections between matter and the dynamics of 'inner' consciousness" (2007, p. 94). In this sense, what we perceive as stable can also be perceived as moving, according to its material and form andevery form may be perceived as moving, even still images.

As dance theorist Ramsay Burt suggests, instead of juxtaposing visuality to temporality, "there is a need to find ways of recognizing and understanding complex interactions between the different levels of 'discourse' on which dance performance may draw" (2009, p. 41). I will thus propose that images in dance are moving and movement becomes visual. Visual methodologies refer to the scholarly study of visual elements in the field of visual art. However, with the advent of performance art, visual studies have become utilized for analyzing the performance experiments of the 1960s and 1970s and thus also movement:

The recent trends show that the body calls forth, as a promise or oath, the transformation of the disciplines that previously contained it. This performativity also involves, in a manner both intrinsic and extrinsic to it, the visual. (Franko \& Soussloff, 2002, p. 38).

I argue for the importance of visual methodologies to dance research and suggest that visuality is intrinsic to bodily movement. I will look at the effects of this relationship and propose that visuality in dance results to sculpture. I will thus suggest that the relationship between dance and sculpture is grounded on relationships between the corporeal and the visual. 
In Visuality in the theatre: The locus of looking - a study on performance perspectivism, theater and performance (2008), theorist Maaike Bleeker proposes that "seeing appears to alter the thing seen and to transform the one seeing, showing them to be profoundly intertwined in the event that is visuality" (p. 2). Thus, in accord to Burt, she sets visuality within a temporal framework by suggesting that the subject who sees affects the object seen in a similar manner as the object being seen changes the subject who sees it. Mitchell (1986), also suggests that "the practice of perspective explicitly inscribes the point of view from which an observation was made and accordingly makes evident the need to recognize the difference a change in viewpoint makes" (p. 46). In Figures 1 and 2, it is the perspective that creates the visual distortions and the effect of moving images. Therefore, showing bodies "from a particular point of view, an image shows more than what can actually be seen" (Bleeker, 2008, p. 47). This process of looking through various perspectives enhanced design variation and pointed to the significance of perspective. Bleeker states that, in painting, to "'get things in perspective' is used as a metaphor to describe seeing things in their true relative proportion, which is actually an odd metaphor since getting the 'right' size, is precisely what perspective falsifies" (2008, p. 14).

\section{Moving Sculptures}

Bleeker's study on perspective is also useful in the theorization of dancing or moving sculptures. As in moving images so in sculptural assemblages, some body parts become accentuated, whereas others are hidden from view. This can also be seen in terms of movement, as some body parts move with greater ease and space projection, whereas others move in restricted or bound flow, to use Laban's term. For example, in the V shape in Figure 3, the legs of the performer on top are free from gravity, and able to perform light movement combinations, while the other performer has to carry the weight, restricting her movements.

"We always see more, and always see less, than what is there to be seen" (Bleeker, 2008, p. 7). Perspective, by obscuring some body parts, unfolded new body images, and new perspectives of the dancing body. For instance, in the $\mathrm{V}$ shape described earlier (Figure 3) (Bleeker, 2008, p. 14), the perspective from which the photograph was taken, by obscuring the performers' torsos, creates a visual continuity between the performers' legs. This visual illusion became accentuated when the assemblage moved through space back and forth as a whole and created the effect of a moving image. Here we can see how the shape of the sculpture entails space and effort. Similarly, in dancing sculptures, perspective was falsified, through moving images, which mixed close with far as in the V shape and created illusions. Illusions were founded on bodily proximity which allowed for mixing some body parts of one body with those of another. In this process, some body parts were obscured while others were visible, from every perspective in a post-structuralist framework that enhances subjective viewing.

Within the post-structuralist framework, theories of embodiment, specifically feminist phenomenological approaches in dance, destabilized the object of theory. Professor in cultural and critical studies, Rachel Fensham, states that "the work of 


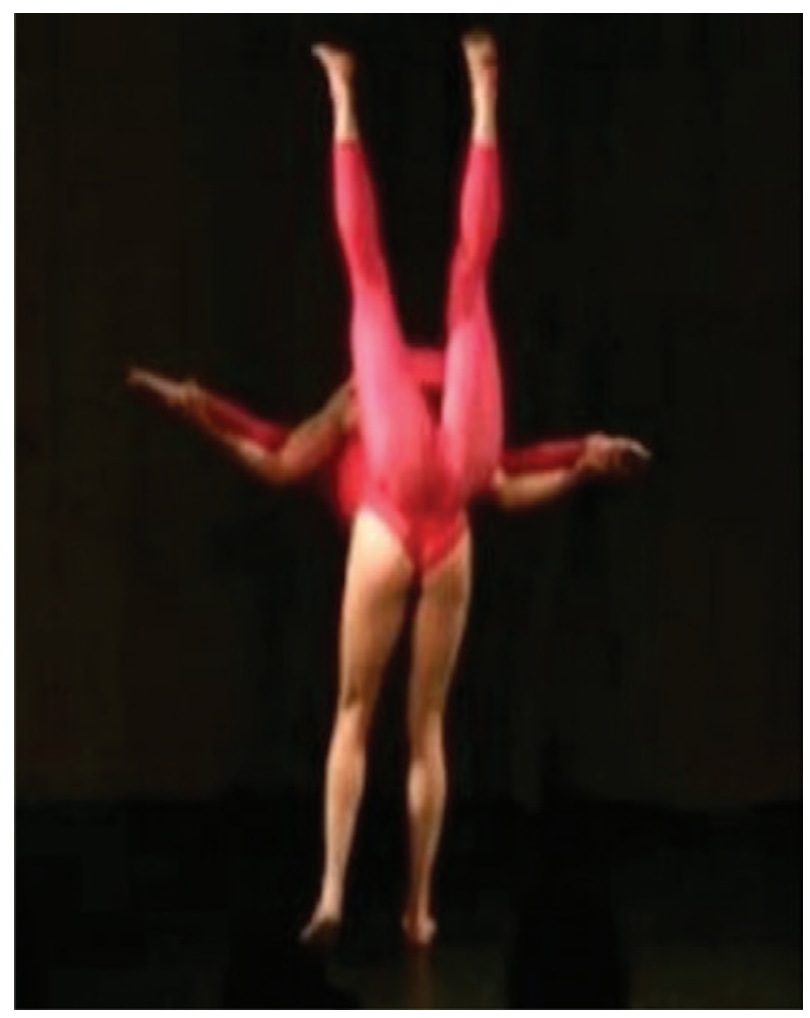

FIGURE 3 | Monster 1,2,3 (2009).

embodiment, from Maurice Merleau-Ponty to Elizabeth Grosz, emphasizes the ontological and subjective dimensions of material existence" (2008, p. 27-28). As Fensham also observed, following Philip Auslander, the post-structuralist approach may have been very productive for understanding modernism, as in Susan Foster's Reading Dancing (1986), but it could not always analyze postmodern performance (2009b, p. 49). This can be partially explained because post-structuralist approaches in dance neglected to account for the objective dimensions of corporeality. In dancing sculptures, the object and subject positions become interchangeable.

In dancing sculptures, there was a blending of mythological figures found in sculptural formations and real bodies constructing them. Dancing sculptures became reminiscent of monsters from Greek mythology, which had awkward anatomies often combining human with animal body parts (Figure 4). For example, the horse assemblage where the torso of one performer is combined with the legs of another was reminiscent of a centaur or the minotaur, a monster with a head of a bull and the body of man. The V shape, combining the legs of one performer with the legs of another, was reminiscent of Actorion, a monster of two conjoined twins sharing one torso in Homer's epic Odyssey. The joining of heads, one next to the other, was reminiscent of the mythic monster Lernaean Hydra, a serpentine beast that had nine heads, and if one was cut off, 


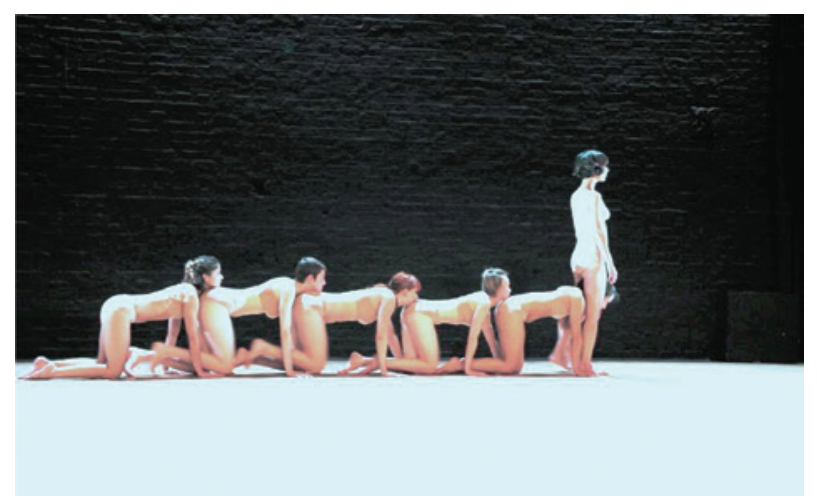

FIGURE $4 \mid \operatorname{Dr}$ Adder (2010).

two more would grow. Heads was also reminiscent of Hecatoncheires, giants who had a hundred arms and fifty heads each. The walking trios, where a performer walks on top of two performers' backs as legs extensions were reminiscent of Cyclops, the giants with one eye.

On the one hand, vision can become 'watching' when it interacts with the other senses. However, 'watching' includes 'seeing', because even when we watch we only see fragments; hence, through a perspective. Seeing and watching, thus, do not exclude each other, but rather, one involves the other. According to literary theorist Ulrika Maude's Modernist Bodies: Coming to our senses (2009), literature and the visual arts "often seem to exploit, even celebrate this dissociation of knowledge and vision by aestheticizing perception, and foregrounding the division between objective knowledge and sensual experience" (p. 122). Similarly, the focus on kinesthesia, by favoring 'watching' over 'seeing', continues to separate subjectivity from objectivity. Maude proposes that quantitative 'seeing' and qualitative 'watching' overlap and that what they share is "an emphasis on wonder" (p. 128), which, I would argue, becomes instigated by simultaneity, that is, by both 'seeing' separately and 'watching' holistically at the same time. This intercorporeal simultaneity demonstrates how extrinsic visual elements to the body's performativity become intrinsic.

In dancing sculptures, seeing what individual bodies were doing, happened simultaneously with watching the illusion of many bodies as one, both in the making and in performance. For instance, in the walking triopresented in Figure 5, the viewer can simultaneously see the individual bodies performing a walk on fours and focus on the awkward points of bodily contact (e.g., foot on back), as well as watch the illusion of a monstrous human figure walking through the visual continuities between the feet of the standing performer and the two performers on fours.

Through this notion of seeing-watching, visual approaches suggest that practice and theory go together and complement each other. As different modes of enquiry, they cannot translate completely because the change in mode also changes the content. However, rather than juxtapose each other as carriers of different ideologies, that is, 


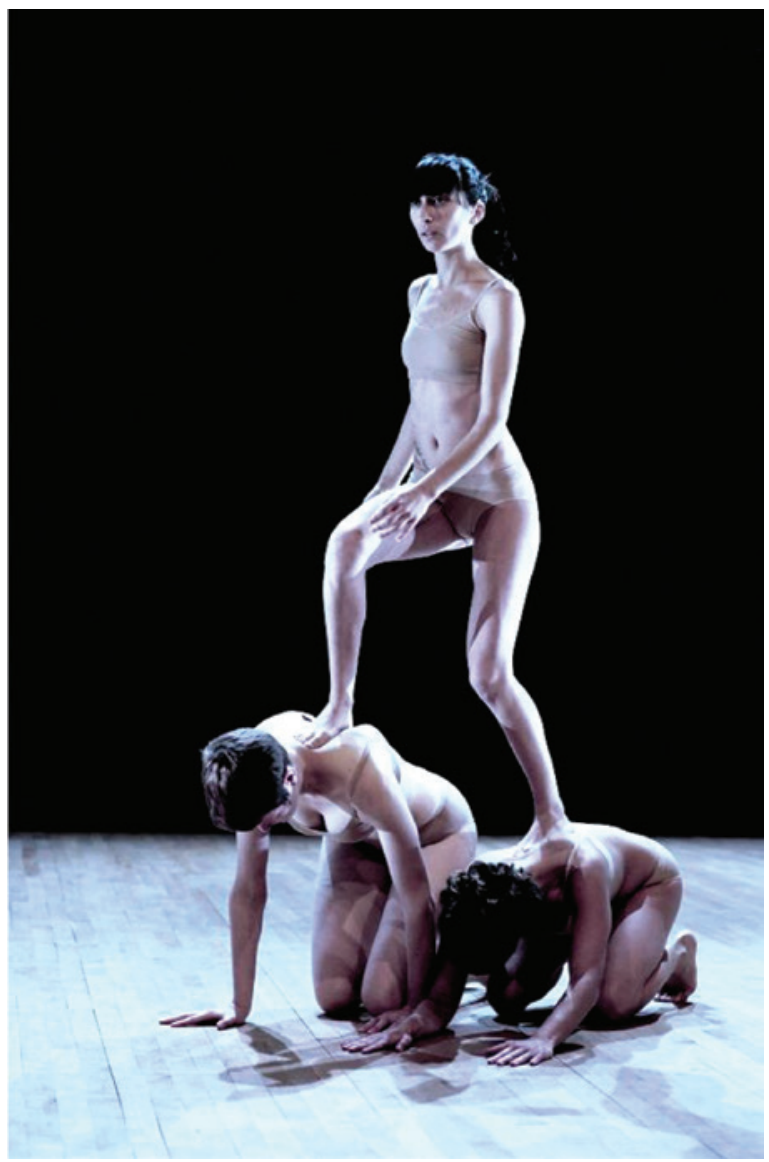

FIGURE 5 | Moving Trio (2010).

deconstructing structuralist theory through subjective expression or the phenomenology of the body, visuality in dance allows an understanding of art disciplines and practice as moving together with theoretical enquiry. Corporeality is thus seen as not only the meeting point of the disciplines but also of contracting various esthetics and ideologies into a new inclusive and intercorporeal assemblage.

Dancing sculptures are a form of what I have termed performance dance, a genre that stands in between performance, art, and dance. Performance dance is a dance practice that moves through art toward performance. Dancing sculptures are a kind of ensemble performance art, extending dance theater into the visual. However, dancing sculptures were created without music, and thus, they created bodily sounds. I will now elaborate moving sounds to complete my theorization of total dance.

\section{Moving Sounds}

Bleeker's discussion (2008, pp. 172-174) of John Martin's writings on the perception of weight (1939), suggests that we perceive weight by seeing it and associating it with 
previous experiences of weight lifting. In the performance Moving Sounds or Banging, weight is perceived through inflicted bodily sounds (Figure 6). Weight and effort were the main instigators of sound.

I will follow a practice-based approach to argue that the nature of the relationship between movement and sound can be primarily examined through the moving body which creates sounds mainly due to gravity but also due to energy. Lynne Anne Blom and L. Tarin Chaplin, in The Intimate Act of Choreography, wrote of the "sounds of movement" and identified that "sometimes the dancer's physical movement provide the accompaniment" as in tap and flamenco dance where "the rhythm that the dancer produces are an integral part of the dance, even a focal point" (1982, p. 160). In such dances, "the dancer is her own musical instrument" (ibid.).

I will now focus on the relationship of movement to sound and particularly on movement inflicted sounds in practice-as-research. In this effort to document ways in which sound and movement interrelate in the act of dancing or moving itself, I examine various examples as they were experienced in my performance works. When the moving body produces sound, it has the capacity, in relative terms, when specific movements are selected, to create phrases of movement and sound synchronicity and of counterpoint. In my approach, both these styles prove to be complementary since ontologically speaking, physical sound is in any way complementary to movement.

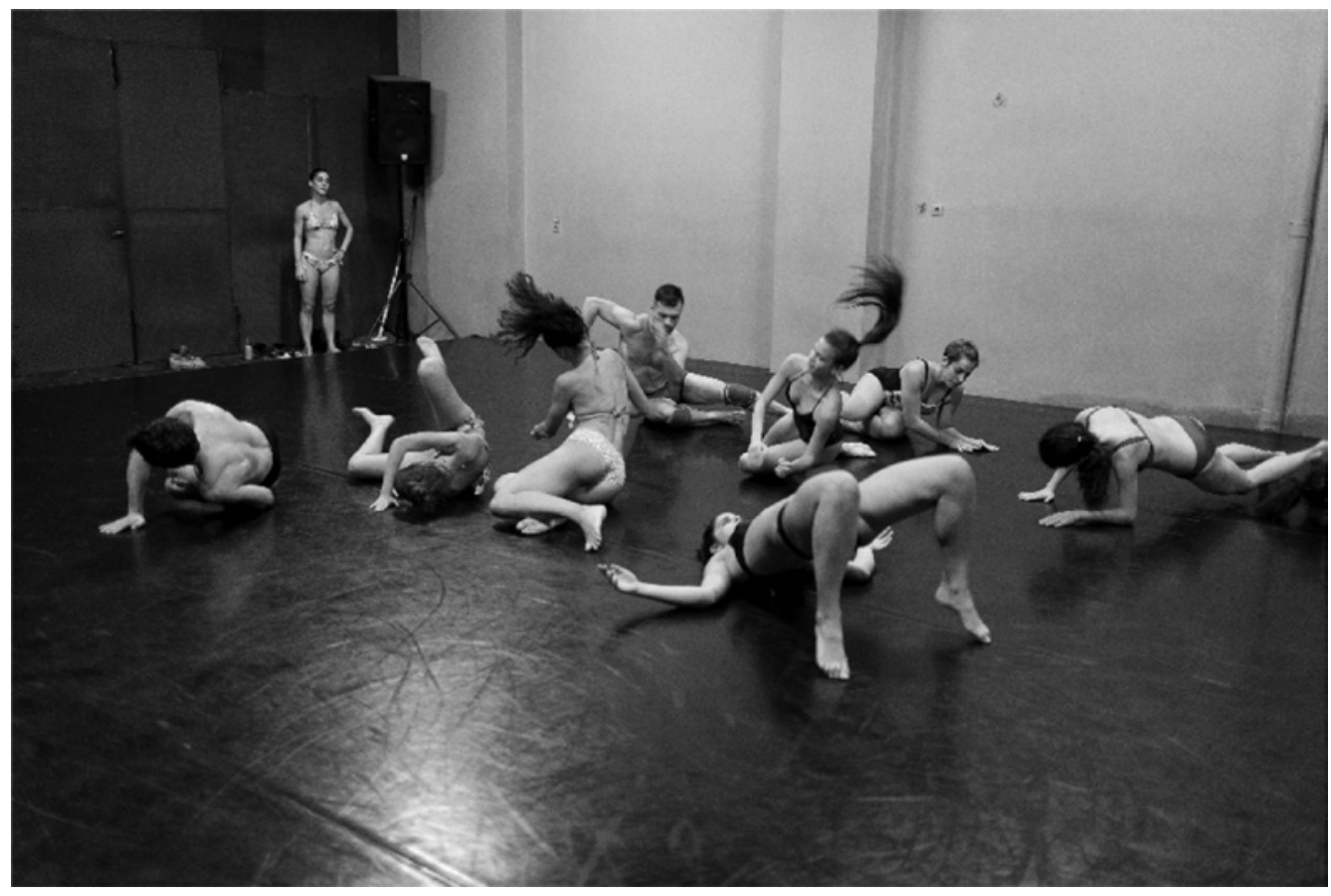

FIGURE 6 | Moving Sounds or Banging (2012). 
Valuable to my analysis are genres such as action-based music and scores that evolved from musical experiments of the 1960s and continue to develop through recent concerns in performance processes. Juraj Kojs (2011), an expert in the field of actionbased music, states that "action-based music entertains the idea that actions can define all aspects of compositional and performance processes" (p. 65) and that in actionbased scores, "the duration of a performance action or gesture becomes the time marker, existing independently from any strict temporal framework" (p. 69). A physical understanding of sound's effort, space, and shape might contribute to measuring and counting time.

I begin my analysis given that sounds are moving. Therefore, sounds have a spatial orientation and direction, a specific shape design, a specific degree of effort or dynamic qualities, and, naturally, specific timing. If movement sounds, then inversely, sound moves. Bodily movement tends to create sounds of great variety that also testify to the varying relationship between them.

In the beginning of the performance, dancers knock their bodies and body parts on the floor, as we can see in Figure 1. When body parts create sounds as they crash to the floor, we witness the weight of sound by its gradual increase in volume and decrease in intervals, the gap between one sound and the next becoming increasingly smaller, and lastly the intensity. This total intensification of sound testifies to the falling quality of weighted sounds or their downward direction. Therefore, we can say that sounds are attracted by gravity in various degrees as different body parts do.

However, there was a parallel or simultaneous upward movement of the sound as body parts hit the floor. Preston-Dunlop defines "spatial projection" as the virtual lines created through space by the performer's movement (2002, p. 6). Similarly, we could say that sound has also a spatial projection, which, in this case, also goes upward, in contrast to the body parts' downward movement. There were movement echoes that allowed tracing where the sound was coming from in space. For example, in the previous falling movement of bodies, there was a simultaneous downward push of the air that rebounded upward and made bodies perceive an upward echo of the sound. This tracing effect shows that movement and sound might work together and in juxtaposition at the same time and with regards to one element. Although bodies moved downward, sound waves moved both in the same and in the opposite direction.

After introducing rhythmical motifs, performers form small groups of two or three, each performing a movement sound in unison and their sounding as a whole becomes reminiscent of an orchestra. Gradually, this bodily orchestra forms two rows of performers lying down to the floor. For example, when dancers lie on the floor and perform a series of banging of body parts on the floor in unison, at some point, they slide their legs and arms upward and downward. The sliding sound suggests a horizontal movement. We could ask if movement and sound move in parallel in this example? In terms of doing, in this example, movement and sound move together in all elements: time, shape, effort, and space. However, visually, we might perceive bodily movement in space as larger or exceeding sound. 


\section{Total Dance}

I define total dance as movement practices that entail images as space, sculptures as shape, and sounds as time. In Figure 5, the moving bodily assemblage of the walking trio creates a space dynamic by forming a different image of the moving body with leg extensions, a shape dynamic as the sculpture moves through space and a time dynamic as the sculpture creates sounds inflicted by bodily weight when the top performer appears to walk. The sound of walking is intensified here as it is produced by the performers on fours that jump forward like bunnies carrying the top performer forward. In this sense, this dancing sculpture is a form of total dance.

When the sculptural assemblage entails moving images and moving sounds, we may speak of total dance being performed. For instance, in Figure 7, we perceive a moving image as the torsos of dancers gradually disappear in the distance. Dancing bodies here acted as chronophotographs that captured movement in successive still images (e.g., Eadweard J. Muybridge, 1830-1904). In addition, the dancers tickle their fingers on the floor, producing a sound of anxiety. The whole sculptural assemblage moves as the first performer lifts her torso and lets it fall to the ground, making a heavy sound, while the last performer lifts her legs and lets them fall to the ground as well. Total dance allows audience and spectators to indulge into a cross-arts event. They can see the moving images and the relationships of the dancers' bodies, watch the whole assemblage movements, and perceive the complex rhythms that are produced in addition to the weight or effort inflicted by moving sounds.

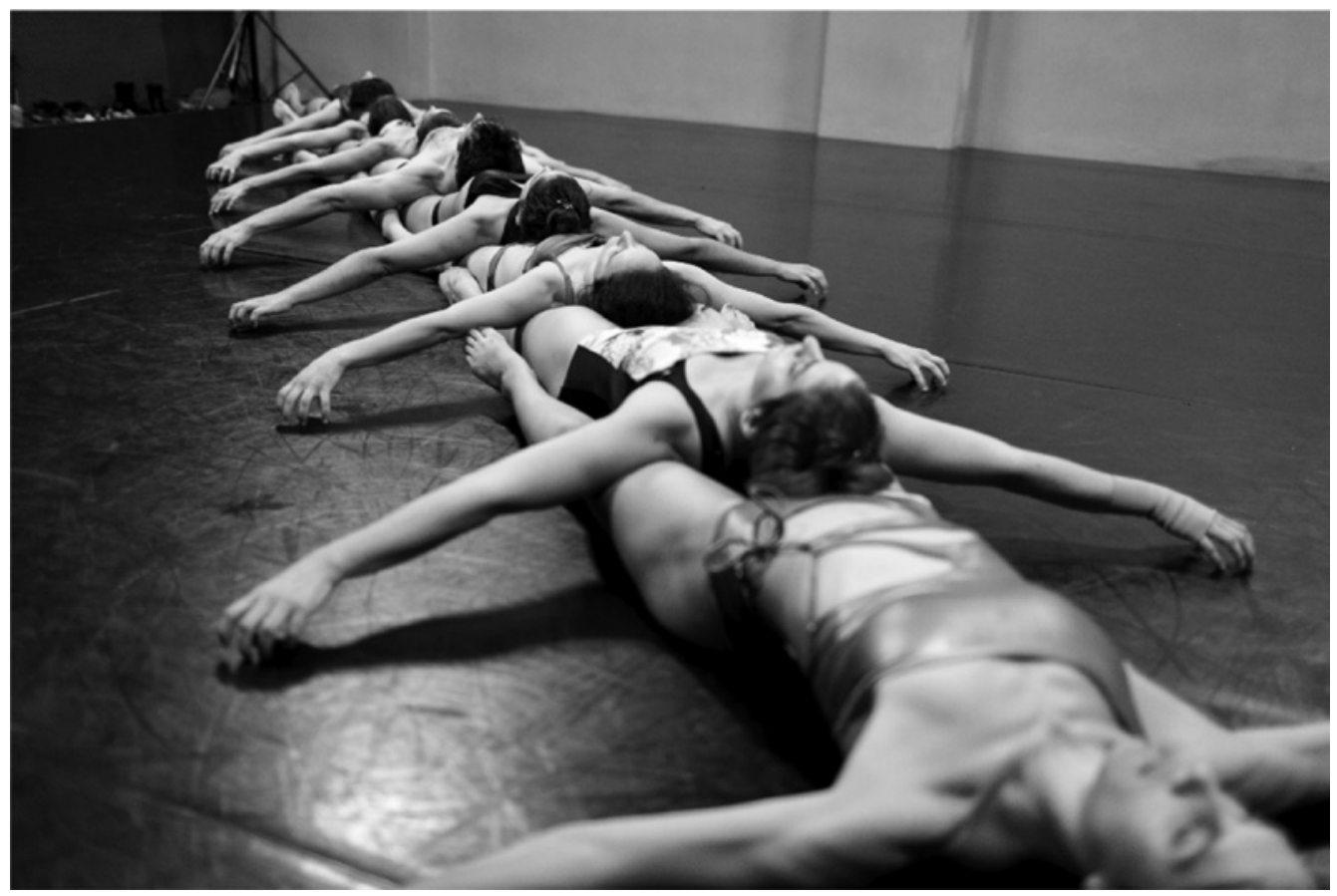

FIGURE 7 | Rear-guards (2012). 
As E.T. Kirby argued about total theater and Richard Wagner about Gesamtkunstwerk or the total artwork in opera that combined image, music, and text, I propose that total dance can produce moving images, moving sounds, and moving sculptures simultaneously. My focus has departed from what dancing bodies do. Dancing bodies always create moving images, sounds, and sculptures consciously or unconsciously. However, in total dance, it was precisely non-dance, which allowed for its potential to become actualized.

\section{Conclusion}

What I want to primarily propose through my analysis is that cooperation between art disciplines is much more productive when it happens from within an art discipline, as dance is here. Instead of combining art disciplines from the outset, bringing together, for example, images and dance or sculpture and dance or music and dance, interdisciplinarity in the arts can happen from within any art discipline. Similar to Laban's model in which effort includes shape, so in arts performance, dance includes sculpture.

What can also be concluded from these articulations of total dance is that movement analysis and corporeality are inherently interdisciplinary. Visuality is necessary for understanding corporeality. Interdisciplinarity is thus proposed to be integrated within the moving body as the primary source of interdisciplinary action, preceding its literary 'origins'. Just as the body constantly encounters with other bodies, so should bodies of knowledge. Intercorporeality is thus not only the meeting point of disciplines, but also that of esthetic genres. Fensham (2009a) argued for the intense relationship between genre and corporeality in the theater. I propose here that the power of corporeality to transform genres lies in its in-betweeness, in the fact that corporeality is always intercorporeality.

Peter Arnold, argues that the esthetic "is a concept which refers to the possibility of perceiving things from a particular point of view" $(2005, \mathrm{p}$. 50). His perception of somesthetic suggests the body as the founding element of esthetic conception. However, it must be said that the intracorporeal perspective, became preferable in time, for allowing more holistic views of the body, which include senses, emotions, and intellect. His term, "movistruct" (p. 59), which refers to the know-how of movement, could perhaps be called "corpostruct"-referring to the body and including both movement and the perception of non-movement. Similarly, his term "movicept" referring to "an identifiable and consciously registered kinaesthetic flow pattern associated with a publicly recognizable action involving movement" (p. 60), could be called "corpocept" to suggest that concepts are created through the body, and can be associated with various ways - of and beyond - its movement.

Thus, an intercorporeal discourse, of "corpostructs" and "corpocepts," could further develop interdisciplinary possibilities through an "intercorpology." As new genres emerge through interdisciplinary methodologies, the possibilities of intercorporeal analysis increase. "Corpostructs" and "corpocepts" could become "interstructs" and "intercepts" that maintain their meaning and significance across various art disciplines. 
The intercorporeal esthetic could then have many applications beyond dance and into the wider field of interdisciplinary performance.

\section{About the Author}

Stefania Mylona is a practitioner-scholar in performance philosophy and performance dance. She studied communication and dance in Athens, Greece. She was awarded the State Scholarship of Greece (I.K.Y.). She completed her MA at Laban and practicebased $\mathrm{PhD}$ in performance at the University of Surrey. She lectured in HE dance and became an associate of the British Higher Education Academy. She received the Glynne Wickham Award from SCUDD (UK) and the Graduate Award from SDHS (USA) while presenting her research internationally. She has convened Performance Philosophy School of Athens, a two-day symposium held in association with the international network Performance Philosophy at E.D.W. and at EMST in Athens. Currently, she is working as a freelance movement teacher, artist, and scholar.

\section{References}

Arnold, P. J. (2005). Somaesthetics, education and the art of dance. Journal of Aesthetic Education, 39, 48-64.

Bleeker, M. (2008). Visuality in the theatre: The locus of looking. Hampshire/New York: Palgrave Macmillan.

Blom, L. A., \& Tarin, C. L. (1982). The intimate act of choreography. Pittsburgh, PA: University of Pittsburgh Press.

Burt, R. (2009). The specter of interdisciplinarity. Dance Research Journal, 41, 3-22.

Fensham, R. (2008). Deconstruction and embodiment: Steps towards the decolonizing of dance discourses. Discourses in Dance, 4, 25-38.

Fensham, R. (2009a). To watch theatre: Essays on genre and corporeality. Brussels: P.I.E.

Fensham, R. (2009b, November). Review of Reading Dancing by Susan Leigh Foster. Times Higher Education, 49.

Franko, M., \& Soussloff, C. (2002, Winter). Visual and performance studies: A new history of interdisciplinarity. Social Text, 73, 20.

Huyssen, A. (1995). Twilight memories: Marking time in a culture of amnesia. London/New York: Routledge.

Kojs, J. (2011). Notating action-based music. Leonardo Music Journal, 21, 65-72.

Laban, R. (1950, ed. 1971). The mastery of movement. London: Macdonald/Evans.

Manning, E. (2007). Politics of touch: Sense, movement, sovereignty. Minneapolis/London: University of Minnesota Press.

Maude, U. (2009). Modernist bodies: Coming to our senses. In U. Maude, C. Saunders, \& J. Macnaughton, The body and the arts (pp. 116-130). UK/New York: Palgrave Macmillan.

Michaud, P.-A. (1998, English trans. 2004). Aby Warburg and the image in motion. New York: Zone Books. Mylona, S. (2007). University of Surrey.

Reynolds, D. (2007). Rhythmic subjects: Uses of energy in the dances of Mary Wigman, Martha Graham and Merce Cunningham. Hampshire: Dance Books. 